\title{
Why the Senior Editor-in-Chief?
}

The scientific community of researchers in the field of headaches is one of the youngest in modern medicine. The era of headache research began in the United States of America in the 1930's with Wolff and in the 1950's in Europe Greppi and his pupil Sicuteri founded another group dedicated to the cure of the patient with headache and to scientific research. (I, as a young student was there!). The Florentine pioneers offer a marked creative driving force and favoured the birth of a broad group of researchers in Italy. For the first time in Europe they formed a multidisciplinary scientific community that was recognised in a unique identity in 1976, under the Italian Society for the Study of Headaches.

The SISC was thus born as an expression of the precious cultural heritage gained after the initial pioneering period, which formed the foundation for a valid group of Italian headache researchers. At the start of the new millennium Professors Gallai and Puca and their collegues at SISC achieved a fundamental objective of the association: estabilishment of The Journal of
Headache and Pain, a symbolic flag for and window on the Society, to express oneself and to communicate on an international level. The recent loss of Gallai and Puca has made the entrance of other forces capable of continuing a project necessary; the project, which is of extreme importance for and must be completed by the SISC, and which must also be an obligation to honour the memories of those deceased.

Why a Senior Editor-in-Chief together with an Editor-in-Chief?

The hope is that in Italy two generations of researchers can merge to help the Journal, not according to the logic of old wine (in this case "Chianti") in a new bottle, but by creating a modern method of production, for The Journal of Headache and Pain and the Italian tradition to achieve a deserved recognition in the world of headaches. I hope, therefore, to be able to contribute to and to see, together with my friend Martelletti, the success of the Journal, and to be able to say with pride yet again, "I was there".

Marcello Fanciullacci Senior Editor-in-Chief 